\title{
Fairness and behavioral intentions in discrete B2B transactions: a study of small business firms
}

\author{
Fabio Cassia \\ Department of Business Administration, University of Verona, Verona, Italy \\ Sven A. Haugland \\ Department of Strategy and Management, Norwegian School of Economics, Bergen, Norway, and \\ Francesca Magno \\ Department of Management, University of Bergamo, Bergamo, Italy
}

\begin{abstract}
Purpose - While studies about business-to-business (B2B) relationships have mainly addressed buyer-supplier long-term exchanges, focusing on social outcomes such as trust, commitment and cooperation, there is little research that explores the social outcomes which stem from short-term B2B transactions. The purpose of this paper is to explain buyers' intention to renew a contract after discrete and time-delimited transactions by suggesting a model that complements social exchange theory with theories of fairness. In detail, this study aims to determine how evaluations of economic and social outcomes are complemented by both procedural fairness and distributive fairness.

Design/methodology/approach - The hypotheses are tested in the social couponing industry with a survey of a sample of 199 firms purchasing advertising services from daily deal websites. Data are analyzed using covariance-based structural equation modeling (CB-SEM).

Findings - The findings reveal direct effects of procedural fairness on social outcomes (satisfaction) and distributive fairness on the intention to renew a contract, negative moderating effect of procedural fairness on the relationship between economic outcomes (campaign effectiveness) and social outcomes (satisfaction).

Research limitations/implications - In discrete, time-delimited transactions, high levels of procedural fairness may partially compensate for low levels of economic outcomes and prevent a reduction in social outcomes. Hence, when economic outcomes are influenced largely by external, uncontrollable conditions, the buyer seems to appreciate the supplier's efforts to behave fairly.

Practical implications - Social outcomes matter even in discrete transactions and considerations of fairness should be integrated in the management of discrete transactions. Sharing economic outcomes fairly is not sufficient to secure the buyer's intention to renew the contract.

Originality/value - This study proposes and tests a model that complements social exchange theory with theories of fairness and explains contract renewal in discrete, time-delimited transactions, encompassing both economic outcomes and social outcomes.
\end{abstract}

Keywords Social exchange theory, Procedural fairness, Distributive fairness, Discrete B2B transactions

Paper type Research paper

\section{Introduction}

Research on business-to-business (B2B) relationships has primarily been concerned with buyer-supplier long-term relational exchange, focusing on the development of outcomes such as trust, commitment and cooperation. Particularly since the 1980s, researchers have suggested a paradigm shift from discrete transactions to long-term relationships (Håkansson, 1982; Morgan and Hunt, 1994). As a result, transactionoriented, short-term exchanges depending on the actors' ability to deliver immediate results have received limited attention (Kronlid and Baraldi, 2020). However, in many B2B contexts the effects of digitalization are causing the reversion to a transactional orientation from a relational orientation (Hofacker et al., 2020). For example, because of the increased

The current issue and full text archive of this journal is available on Emerald Insight at: https://www.emerald.com/insight/0885-8624.htm

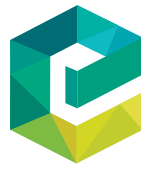

Journal of Business \& Industrial Marketing 36/13 (2021) 129-141

Emerald Publishing Limited [ISSN 0885-8624] [DOI 10.1108/JBIM-12-2019-0538] volume of online transactions in B2B markets, single transactions and changing suppliers and customers can be achieved easily.

Current understanding of the mechanisms governing discrete, transaction-oriented exchanges is limited because past research is scarce and conceptually suggests that available knowledge about long-term relationships cannot be extended to transaction-oriented and short-term exchanges. The reasons are that committed relationships take time to develop and that the expectation of future transactions is low in transaction-

\footnotetext{
(C) Fabio Cassia, Sven A. Haugland and Francesca Magno. Published by Emerald Group Publishing Limited. This article is published under the Creative Commons Attribution (CC BY 4.0) licence. Anyone may reproduce, distribute, translate and create derivative works of this article (for both commercial and non-commercial purposes), subject to full attribution to the original publication and authors. The full terms of this licence may be seen at http://creativecommons.org/licences/by/4.0/legalcode
}

Received 18 December 2019

Revised 17 June 2020

10 October 2020

26 February 2021

Accepted 1 April 2021 
oriented, short-term exchanges (Lambe et al., 2000). However, as empirical evidence is remarkably scarce, it is still unclear to which point the mechanisms governing long-term relationships can or cannot be extended to transaction-oriented exchanges.

To address this knowledge gap, we draw in this study on social exchange theory (SET), which represents an important theoretical framework for studying B2B relationships. Because of its focus on evaluations of economic and social outcomes as important dimensions for an understanding of the development of long-term, committed relationships, SET has been frequently used to study relational exchange (Lambe et al., 2001). However, conceptual research has suggested that SET cannot be applied to transaction-oriented, short-term exchanges because social aspects cannot emerge within a limited timeframe (Lambe et al., 2001). Nonetheless, recent evidence from case-specific research questions this conclusion, indicating that some social outcomes emerge also in time-constrained interactions and can sometimes represent the starting point to build future durable relationships (Kronlid and Baraldi, 2020).

Discrete transactions are usually considered the opposite of relational exchange. Macneil (1980, p. 60) describes discreteness as "the separating of a transaction from all else between the participants at the same time and before and after," and discrete transactions will usually have defined starting and ending points in time. Discrete transactions are single transactions within a designated timeframe without any further commitment from neither buyer nor seller to continue with further transactions. Buyer and seller agree on one, single transaction at a time, and there is no obligation to enter new transactions. This does not mean that buyer and seller cannot enter new transactions, but there is no up-front agreement or commitment beyond the specific transaction in question.

We examine the economic and social outcomes of discrete exchanges with a fixed or delimited duration through SET as the theoretical starting point. However, because the evaluations of both economic and social outcomes are limited in discrete, timedelimited exchanges, we argue that the evaluation of the fairness of exchange processes represents an important determinant, which complements evaluations of economic and social outcomes. In fact, fairness perceptions arise from the early stage of relationships (Crosno and Dahlstrom, 2011). Studies show that fairness is important for developing good relationship quality and long-lasting relationships (Brown et al., 2006; Griffith et al., 2006; Kim et al., 2017; Kim et al., 2019; Kumar et al., 1995; Mutonyi et al., 2018; Samaha et al., 2011; Wagner et al., 2011), while unfairness damages relationships (Samaha et al., 2011).

Theoretically, we study discrete, time-delimited transactions through the combination of SET with the theory of fairness by considering the chain linking buyers' perceived value to behavioral intention (repurchase, dissolution intention, search for alternatives, etc.) through satisfaction (Eggert and Ulaga, 2002; Williams et al., 2011). The chain suggests that buyers' evaluation of perceived value directly affects satisfaction, which, in turn, is a direct antecedent of behavioral intention (Eggert and Ulaga, 2002). Particularly, this study extends our knowledge of how perceived value and satisfaction as indicators of economic and social outcomes, respectively, are linked to behavioral intention. Following past studies on the distinct effects of two components of fairness - procedural fairness and distributive fairness - we link these two components of fairness to the perceived value- satisfaction-behavioral intention chain and explore whether fairness directly affects the components of the chain and moderates the chain linkages by considering the direct and moderating effects of both procedural fairness and distributive fairness.

We test the hypotheses in the social couponing industry through a survey of a sample of firms such as hotels, restaurants and other service providers (i.e. the buyers in our study) that purchase advertising services from daily deal websites, such as Groupon ${ }^{\mathrm{TM}}$ (i.e. the suppliers in our study). Firms usually agree to purchase a campaign from a daily deal website (i.e. the opportunity to sell a certain number of coupons through that site) for a designated time period, which has defined starting and ending points in time (Kumar and Rajan, 2012; Sigala, 2013). We consider this context particularly relevant as it allows us to focus on discrete, timedelimited transactions where firms buy a campaign. Therefore, we can evaluate the buyer's perceived value of the campaign, satisfaction with the daily deal website and intention to buy another campaign from the daily deal website. Further, we can link buyers' perceptions of fairness in their interactions with the daily deal website throughout the campaign period to their satisfaction and behavioral intention. This context offers a unique opportunity to explore evaluations of both outcomes and fairness in discrete, time-delimited exchanges and the consequences of these evaluations to continue transacting with the same partner by renewing the contract for another purchase.

This study contributes to our knowledge of how actors evaluate transaction-oriented exchanges and how such evaluations affect intentions to continue transacting with the same partner. As the number of discrete and often one-time B2B transactions without any specific intention to develop a long-term relationship increases, such knowledge can contribute to a broader understanding of buyers' evaluations of discrete exchanges that affect their intention of future exchanges with the supplier.

\section{Theory and hypotheses}

\subsection{Social exchange theory and fairness}

SET is commonly used to analyze B2B relationships (Lambe et al., 2001; Ling-yee, 2010; Narasimhan et al., 2009; Shanka and Buvik, 2019). SET analyzes social behavior in terms of exchanges (Homans, 1958), and the core of SET can be described as follows: "Social exchange comprises actions contingent on the rewarding actions of others, which over time provide for mutually and rewarding transactions and relationships" (Cropanzano and Mitchell, 2005, p. 890). A basic premise of SET is that exchanges have both social and economic outcomes (Blau, 1964; Emerson, 1976; Lambe et al., 2001). B2B relationships develop over time based on the actors' evaluations of both outcomes. Lambe et al. (2001, p. 5-6) note the following: "SET postulates that exchange interactions involve economic and/or social outcomes. Over time, each party in the exchange relationship compares the social and economic outcomes from these interactions to those available from exchange alternatives which determines their dependence on the exchange relationship."

Emerson (1976, p. 336) argues that SET is not a theory but rather "a frame of reference within which many theories - some micro and some macro - can speak to one another, whether in argument or mutual support." For example, SET can serve as a framework for explaining the development of relational 
exchange characterized by trust and commitment (Lambe et al., 2001). The core argument is that exchanges are interactive and gradually develop over time based on the actors' evaluations of both economic and social outcomes. Positive outcomes during the early stages of an exchange process increase the likelihood of continued exchanges that develop into relational exchange. In contrast, early negative outcomes may lead to an early relationship termination.

However, while SET has been extensively used to understand buyer-supplier long-term relational exchange, research suggests that it has limited ability to explain the development of governance mechanisms in short-term exchange or in exchange relationships that must produce results quickly (Lambe et al., 2001). The main reason for this conclusion is that short-term exchanges lack sufficient time for social outcomes-such as, for example, trust and commitment-to emerge between the parties (Peters and Pressey, 2016). The link between relationship duration and social outcomes has been extensively documented in past research showing that the longer the duration of buyersupplier relationships, the stronger the social bonds among the parties (Shanka and Buvik, 2019). Nonetheless, researchers have noted that even short-term exchanges cannot be understood only by considering economic aspects, and that social components can matter in this context as well (Nevin, 1995). While empirical research on these issues has been scarce, recent work provides some evidence that some social outcomes emerge in timeconstrained interactions (Kronlid and Baraldi, 2020). Therefore, we argue that SET is valuable also for studying exchanges of shorter duration such as discrete, time-delimited transactions.

Because evaluations of both economic and social outcomes are limited in discrete, time-delimited exchanges, we complement SET with theory of fairness to explain how earlystage evaluations of both economic and social outcomes affect future intentions to renew the contract. In fact, fairness theory indicates that fairness judgments are already made at the early stages of a relationship (Crosno and Dahlstrom, 2011; Lind et al., 2001). Fairness refers to the perception by a person that a decision, outcome or procedure is both balanced and correct (Husted and Folger, 2004; Poppo and Zhou, 2014; Sheppard et al., 1992). In applying theory of fairness or justice to management studies, researchers commonly distinguish between distributive fairness, procedural fairness and interactional fairness (Ariño and Ring, 2010; Bouazzaoui et al., 2020). Distributive fairness concerns evaluations of how outcomes are allocated or shared, procedural fairness relates to the procedures and processes used to make allocation decisions, and interactional fairness describes the ways the partners are treated (Ariño and Ring, 2010; Poppo and Zhou, 2014).

In studies of B2B relationships, it is most common to apply distributive fairness and procedural fairness. Because interactional fairness relates to the treatment of individuals, this fairness dimension is commonly used within organizations and used less often in studies of inter-firm relationships. Thus, in this study, we focus on procedural and distributive fairness. In a B2B context, procedural fairness (also called procedural justice) refers to buyers' perception of "the fairness of the supplier's procedures and processes" in relation to its customers (Kumar et al., 1995, p. 55), including giving a voice to those subject to the procedures (Poppo and Zhou, 2014).
It covers aspects such as the supplier's willingness to engage in bilateral communication with the customer and to explain its policies (Kumar et al., 1995). Distributive fairness (also called distributive justice or pie-sharing fairness) (Wölfel and GrosseRuyken, 2019) refers to a customer's perception of "the fairness of earnings and other outcomes that it receives from its relationship with the supplier" (Kumar et al., 1995, p. 55), that is, a customer's evaluation of the "benefits or rewards in proportion to [its] own relative efforts or inputs" (Samaha et al., 2011, p. 102).

In sum, we argue that actors' evaluations of both distributive and procedural fairness may complement the limited evaluations of economic and social outcomes in determining whether to continue with further exchanges by renewing a contract after a discrete, time-delimited transaction. After an initial exchange, if an actor does not possess enough information to make a valid evaluation of the outcomes, the actor's perception of fairness may instead serve as a reference point for deciding whether to continue exchanges with the same partner.

Single, discrete transactions delimited in time are increasingly relevant because of B2B digital evolutions, which have changed the way buyers behave and make sense of value and exchanges (Hofacker et al., 2020). Such changes have been studied in terms of lower transaction costs (Peppard and Rylander, 2006) and faster transaction times (Gustafson et al., 2019). In detail, research shows that in the case of digital transactions, it is easier and less costly for buyers to switch between suppliers, which results in higher churn rates (Gustafson et al., 2019). The model developed in this study can therefore contribute to understanding the intention to renew or churn in discrete, time-delimited exchanges (Janita and Miranda, 2013).

In the following, we develop hypotheses linking distributive and procedural fairness to economic and social outcomes. We first propose two hypotheses related to the effects of economic and social outcomes, and then we link distributive and procedural fairness to outcomes and future intentions to continue the exchange relationship.

\subsection{Hypotheses}

\subsubsection{Outcomes and future intentions}

Evaluations of both economic and social outcomes are key tenets of SET. We apply this logic by using the perceived valuesatisfaction-behavioral intention chain suggested by Eggert and Ulaga (2002) as a baseline model. The perceived value of an exchange is an indicator of the economic outcomes; satisfaction with the collaboration represents the social outcomes, and behavioral intention concerns the decision to enter new exchanges with the partner, dissolve the relationship, or search for alternatives. The chain suggests that a direct, positive relationship exists between perceived value and satisfaction and between satisfaction and behavioral intention. The chain has been largely supported in past research (Human and Naudé, 2014).

Perceived value is a cognitive construct based on a process of cognitive comparisons, while satisfaction is an affective response to an evaluation (Eggert and Ulaga, 2002; Oliver, 1996). Eggert and Ulaga (2002) argue that satisfaction is a type of post-purchase evaluation, while perceived value is 
independent of when a product or service is purchased, and judgments of perceived value can be made both before and after a purchase. Because perceived value is a cognitive construct and satisfaction is an affective response to an evaluation, we argue that these constructs are viable indicators of economic and social outcomes.

Considering this study's specific research setting (i.e. social couponing) and past research on the relationship between advertising/marketing service providers and buyers (Bennett et al., 2005; Levin et al., 2019), we specify the aforementioned chain as follows. The perceived value is expressed in terms of the perceived tangible benefits provided by the couponing campaign. We describe this phenomenon as campaign effectiveness and define it as a post-purchase evaluation of how effective the buyer experiences the couponing campaign. For example, a buyer such as a hotel will view the couponing campaign as effective if it has increased room occupancy rate and revenues. Satisfaction reflects a buyer's level of satisfaction with his or her relationship with the daily deal website, and behavioral intention is specified as the intention to renew the contract with the website for a new social couponing campaign. The perceived value-satisfaction-behavioral intention chain has received empirical support (Human and Naudé, 2014; Padilla et al., 2017; Ruiz-Martínez et al., 2019), and the chain represents our baseline model anchored within SET logic. Thus, we propose the following two hypotheses:

H1. A buyer's perceived campaign effectiveness is a direct and positive driver of satisfaction.

H2. A buyer's satisfaction is a direct and positive driver of the intention to renew the contract.

\subsubsection{Direct and moderating effects of fairness}

We suggest that because procedural fairness is related to actors' evaluation of the fairness of the procedures and processes used within the buyer-supplier relationship, procedural fairness is most likely to influence social outcomes or the affective dimension (i.e. satisfaction). If a buyer experiences the processes and procedures to be unfair, for example when the procedures and processes are established mainly by a supplier who is unwilling to engage in bilateral communication, this judgment is likely to influence the buyer's affective response to his or her evaluation of the supplier in terms of social benefits.

In contrast, distributive fairness, which reflects how earnings and benefits are shared between the buyer and supplier, is more likely to affect behavioral intention (i.e. the intention to renew the contract for future purchases). If the supplier captures a larger share of earnings and outcomes than the buyer considers fair, the buyer's intentions regarding future behavior are likely to be influenced. First, we link procedural fairness to the relationship between campaign effectiveness (i.e. economic outcomes) and satisfaction, and then we link distributive fairness to the relationship between satisfaction (i.e. social outcomes) and the intention to renew the contract (i.e. behavioral intention).

Past studies highlight that procedural fairness has a strong positive effect on the quality of the buyer-supplier relationship (Griffith et al., 2006). While relationship performance is not entirely dependent on the behavior of the supplier, procedural fairness perceptions are directly attributed to the supplier, and such perceptions are stable over time (Kumar et al., 1995). Hence, in the case of unfairness, the buyer perceives an emotional imperative to punish unfair partners because of the intentionality of such unfairness (Samaha et al., 2011). Following this reasoning, we posit that procedural fairness has a direct effect on affective output (Eggert and Ulaga, 2002), that is, on the buyer's satisfaction. For example, a key decision in designing a couponing campaign is the number of coupons to be sold, which is a central point in the transaction between the supplier (i.e. the daily deal website) and the buyer (e.g. the hotel). While the daily deal website is interested in setting a high number of coupons to earn more commissions, the customer aims at selling the "right" number of coupons to avoid service failures due to an excessive volume of customers. For example, a hotel may have a coupon campaign with breakfast included in the room rate. If the hotel has limited capacity to serve the guests breakfast, a high number of coupons may result in failure of delivering the demanded number of breakfasts (Berezina et al., 2016). Hence, if the buyer perceives that the number of coupons is not imposed by the daily deal website but is the result of negotiations, this will likely increase the level of perceived procedural fairness, which in turn will improve satisfaction.

In addition, we suggest that procedural fairness negatively moderates the relationship between campaign effectiveness and satisfaction. In other words, if procedural fairness is high, a buyer's satisfaction may still be high even if campaign effectiveness is low. This moderation effect reflects a buyer's perception that procedural fairness is the result of a supplier's intentional behavior, while campaign effectiveness is not. We base this argument on the interaction between economic and social aspects in long-term B2B relationships and apply the reasoning to discrete, time-delimited exchanges (Bouazzaoui et al., 2020). In particular, we draw on studies on performance attribution in B2B relationships arguing that relational mechanisms can mitigate buyer and supplier reciprocal blame attribution for low performance (Selviaridis, 2016). In a similar way, we propose that if the buyer perceives the procedures and processes used within the relationship to be fair, the buyer may still positively evaluate his or her relationship with the daily deal website (i.e. a high level of satisfaction) even if he or she believes that the campaign has not been very successful. In contrast, a low level of procedural fairness may result in low satisfaction, even in a highly effective campaign. When the buyer perceives that the supplier cannot guarantee the economic outcomes because of the presence of uncontrollable factors, procedural fairness becomes important in explaining social outcomes such as satisfaction (Kumar et al., 1995). For example, if a buyer experiences that the social couponing campaign has underperformed compared with expectations (e.g. only a small number of coupons were sold), the buyer's satisfaction will be higher in the case he or she perceives that the decisions about the design of the campaign (e.g. duration of the campaign and services included in the coupon) were jointly discussed with the daily deal website (high fairness) compared with the case where the terms were completely imposed by the daily deal website (low fairness). In sum, a high level of procedural fairness may serve to compensate for low campaign effectiveness, while a low 
level of procedural fairness may undermine an effective campaign. Hence, we propose the following:

H3. Procedural fairness has both a direct, positive effect on satisfaction $(\mathrm{H} 3 \mathrm{a})$ and a negative moderating effect on the relationship between campaign effectiveness and satisfaction $(H 3 b)$.

Past research finds that distributive fairness is critical to the stability of contractual recurrence (Poppo and Zhou, 2014). In fact, the perception that each party has received a fair return provides the incentive to continue a relationship (Poppo and Zhou, 2014). Similarly, Wagner et al. (2011) find that outcome fairness (i.e. distributive fairness) has a significant direct effect on a buyer's expectations of relationship continuity. Conversely, the degree to which the distribution of rewards relative to efforts is inequitable is an antecedent to the intention to dissolve the relationship (Samaha et al., 2011). On the basis of past studies, we hypothesize that distributive fairness has a direct impact on conative or behavioral output (Eggert and Ulaga, 2002), that is, the intention to renew the contract.

In addition, we suggest that distributive fairness negatively moderates the relationship between satisfaction and the intention to renew the contract. Distributive justice is especially important when partners are more concerned for their shortterm interests than for their common interests, making cooperation and commitment less relevant (Dong et al., 2019). We argue that in discrete, time-delimited exchanges, buyers' evaluations of distributive fairness may complement the limited evaluations of social outcomes in determining whether to enter future exchanges. Buyers' overall impression of distributive fairness has a strong influence on behaviors when knowledge among the parties is limited, such as in the early stage of relationships and in short-term relationships (Crosno and Dahlstrom, 2011). In these situations, distributive fairness acts as a heuristic reducing the influence of other factors such as relationship quality (Lind et al., 2001). Thus, when distributive fairness is high, the intention to renew the contract for future exchanges may also be high, even if satisfaction is low. If the buyer perceives that the distribution of outcomes is fair, the buyer may still want to renew the contract even if he or she is not highly satisfied with his or her relationship with the daily deal website. However, if distributive fairness is low, the buyer may be unwilling to renew the contract despite being highly satisfied. For example, in the couponing industry, if a buyer (e.g. a restaurant) perceives that the commissions to be paid to the daily deal website expressed as a percentage of the coupon face value are fair (high distributive value), he or she may be willing to renew the contract for another campaign, regardless of the level of overall satisfaction with the daily deal website.

A high level of distributive fairness may thus compensate for a low level of satisfaction, and a low level of distributive fairness may undermine a high level of satisfaction. Therefore, we hypothesize the following:

H4. Distributive fairness has both a direct, positive effect on the intention to renew the contract $(\mathrm{H} 4 \mathrm{a})$ and a negative moderating effect on the relationship between satisfaction and the intention to renew the contract $(H 4 b)$.
The relationships between the variables are depicted in Figure 1.

\section{Methods and data}

\subsection{Research context, data collection and sample description}

We conducted a questionnaire-based survey in Italy's social couponing (or flash sale) industry. Social coupons are prepaid online discount vouchers sold by firms (such as hotels, restaurants and other service providers) through daily deal websites or platforms (such as Groupon ${ }^{\mathrm{TM}}$ and many other local and global websites) (Kumar and Rajan, 2012; Sigala, 2013). The focus of this study is on the inter-organizational relationships between firms buying couponing campaigns and the websites supplying them. Past studies in this industry highlight that a well-functioning relationship between the firm and the daily deal platform provider is pivotal for the success of social couponing campaigns (Berezina et al., 2016; Cassia et al., 2015). When proper cooperation between the firm and the platform is lacking, issues such as, for example, inaccurate or misleading description of what is included in the deal can arise, which may cause customer disappointment, even if neither the firm nor the daily deal website can be considered entirely at fault (Cox, 2015).

The campaigns have three phases. First, the firm and the daily deal website negotiate and agree on the campaign terms. The contracts between the websites and the firms are highly standardized and negotiations are limited to issues such as content of the firms' offerings (e.g. two-night stay at a hotel, restaurant dinner, etc.), the period for purchasing the coupons (feature period), maximum number of coupons that the website can sell, expiration date to redeem the coupons, and remittance amount (the amount of money the website will remit to the firms for each sold coupon). In some cases, the feature period is decided by the website. The negotiation period usually takes around two weeks. Second, there is a period where customers can buy the coupons, and third, there is a final deadline for redeeming coupons. The periods for buying and redeeming coupons vary, but two weeks for buying and between two and four months for redeeming are quite common. Figure 2 illustrates the three periods. Usually, within a month after the end of the campaign period, the website and the firm evaluate the performance of the campaign. The firms buy one campaign at a time which has defined starting and ending time points. There is no commitment of future purchases although firms may buy repeated campaigns. This makes the context appropriate for investigating discrete, timedelimited B2B exchanges.

\section{Figure 1 Research model}

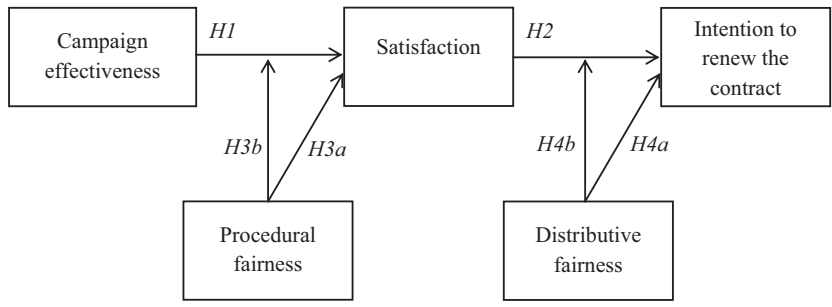


Figure 2 Exchange phases

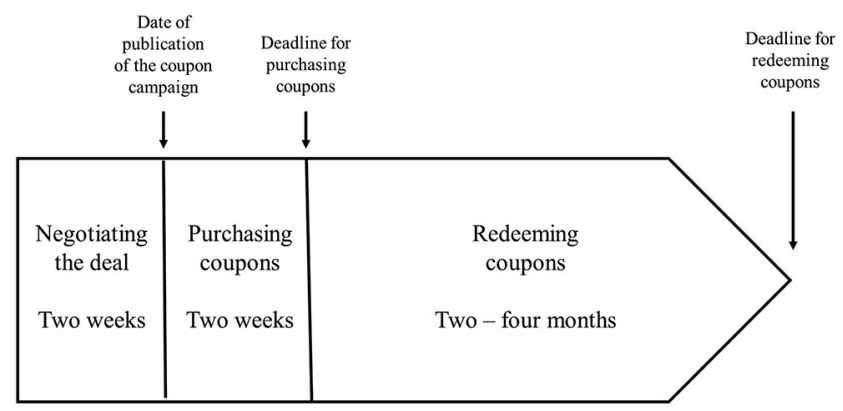

We collected data from firms that had offered coupons through two daily deal websites. First, we considered a local website operating in the north of Italy. We checked the platform provider's website to collect information regarding firms that had launched social couponing campaigns on the website over a three-year period. Then, we visited each firm's website (when available) to find the firm's e-mail address. In addition, we considered a global daily deal website and subscribed to its daily deal newsletters targeted at four different cities in the north of Italy. We analyzed all deals in the newsletters over one year and followed a procedure similar to that described above to collect the firms' e-mail addresses. Overall, we collected 1,247 e-mail addresses: 696 from the local website and 551 from the global website.

Each firm was sent an e-mail with a link to the online questionnaire and a presentation of the purpose of the research project. This invitation was sent approximately one year after each firm's social couponing campaign had been completed to make sure that respondents had a clear understanding of the campaign's effectiveness. We received 299 questionnaires, and 24 were deleted because of incomplete answers. In addition, we excluded from the analysis the questionnaires of respondents ( $\mathrm{n}$ $=76$ ) that had run three or more social couponing campaigns. As the focus of this study is on discrete, time-delimited transactions instead of long-term relationships, we were interested in respondents with limited experience with couponing campaigns. The final sample consists of 199 responses (118 from the local website and 81 from the global website). The average number of days to purchase the coupons is 13.86 , the average number of days for using the coupons is 111.25 , and the average total number of days is 125.11 . Including the up-front negotiation period of two weeks, the entire transaction period is on average about 4.5 months. Table 1 shows the descriptive statistics of the sample. The participating firms - all of which are small- or medium-sized belong to a variety of industries, most frequently represented by restaurants and beauty and wellness services.

\subsection{Measures and data analysis}

Each construct was measured through multi-item scales derived from past studies and adapted slightly to the research setting. The selection of the scales was based on two main criteria: their strength in reflecting the intended content validity and their well-established usage in inter-organizational studies. Only for the construct "campaign effectiveness" did we select a scale specifically developed and tested in the social couponing
Table 1 Respondent profiles

\begin{tabular}{lr}
\hline Variable & Frequency ( $=199)$ \\
\hline Industry & $47(23.6 \%)$ \\
Restaurants & $38(19.1 \%)$ \\
Beauty and wellness services & $28(14.1 \%)$ \\
Hotels and other accommodation services & $14(7.0 \%)$ \\
Health services & $9(4.5 \%)$ \\
Travel services & $63(31.7 \%)$ \\
Others & \\
Number of employees & \\
$1-3$ & $142(71.4 \%)$ \\
$4-5$ & $28(14.1 \%)$ \\
$6-10$ & $20(10.0 \%)$ \\
$11-20$ & $5(2.5 \%)$ \\
$21-50$ & $2(1.0 \%)$ \\
$51-250$ & $2(1.0 \%)$ \\
Number of coupon campaigns run to date & \\
1 & $104(52.3 \%)$ \\
2 & $95(47.7 \%)$ \\
Average number of coupons sold per campaign & \\
Less than 50 & $80(40.2 \%)$ \\
From 51 to 100 & $48(24.1 \%)$ \\
From 101 to 200 & $28(14.1 \%)$ \\
From 201 to 500 & $27(13.6 \%)$ \\
More than 500 & $16(8.0 \%)$ \\
\hline
\end{tabular}

industry to be able to grasp the meaning that buyers attribute to effectiveness in this specific context. The effectiveness of each social couponing campaign was measured on a three-item scale from Cassia et al. (2015), registering the extent to which the campaign successfully contributed to reaching the firm's marketing goals. Satisfaction with the collaboration was assessed on the basis of four items from Jap (2001) and Cannon and Perreault (1999). The firm's intention to renew the contract with the daily deal website for another couponing campaign was measured using three items adapted from Roberts and Merrilees (2007). Procedural fairness and distributive fairness were measured by five items from Kumar et al. (1995) and by three items from Poppo and Zhou (2014), respectively. Table 2 shows the complete list of items. All items were measured on Likert-type, seven-point scales, except for the three items capturing campaign effectiveness, which were evaluated on five-point scales with "very low" at one end and "very high" at the other end.

Moreover, two control variables were included in the analysis. First, we control for the number of employees because larger firms may have greater negotiation power, thus diminishing the role of fairness. Second, we considered the average number of coupons sold per campaign as a proxy for a firm's involvement in the campaign. Given a low number of sold coupons, a respondent may not be willing or able to engage in an informed evaluation of the campaign and of the relationship with the platform provider.

Finally, we evaluated non-response bias by comparing early and late respondents using $\chi^{2}$ tests and $t$-tests with several key variables, as suggested by Armstrong and Overton (1977). The analysis indicated no significant difference. Data were than 
Table 2 The measurement model

\begin{tabular}{|c|c|c|c|c|c|}
\hline Construct & Item & Mean & SD & C.R. & Factor loading \\
\hline \multirow[t]{4}{*}{ Campaign effectiveness } & Perceived campaign effectiveness related to: & & & & \\
\hline & Acquiring and retaining new customers & 2.58 & 1.32 & I & 0.84 \\
\hline & Increasing brand awareness & 2.73 & 1.25 & 13.66 & 0.84 \\
\hline & Balancing seasonality & 2.31 & 1.24 & 11.32 & 0.73 \\
\hline \multirow[t]{4}{*}{ Satisfaction } & $\begin{array}{l}\text { The collaboration with [Brand of daily deal website] has been a successful } \\
\text { one }\end{array}$ & 4.59 & 1.91 & I & 0.91 \\
\hline & $\begin{array}{l}\text { The collaboration with [Brand of daily deal website] exceeded our firm's } \\
\text { expectations }\end{array}$ & 3.66 & 2.00 & 16.95 & 0.83 \\
\hline & $\begin{array}{l}\text { Our firm is satisfied with the outcomes of the collaboration with [Brand of } \\
\text { daily deal website] }\end{array}$ & 3.78 & 1.89 & 22.35 & 0.92 \\
\hline & Overall, we are very satisfied with [Brand of daily deal website] & 3.85 & 1.98 & 25.04 & 0.96 \\
\hline \multirow[t]{3}{*}{$\begin{array}{l}\text { Intention to renew the } \\
\text { contract }\end{array}$} & $\begin{array}{l}\text { We will likely renew our contract with [Brand of daily deal website] for } \\
\text { another coupon campaign with the existing conditions }\end{array}$ & 3.45 & 2.14 & I & 0.93 \\
\hline & $\begin{array}{l}\text { We are keen to renew our business relationship with [Brand of daily deal } \\
\text { website] for another coupon campaign with the existing conditions }\end{array}$ & 3.19 & 2.10 & 26.29 & 0.96 \\
\hline & $\begin{array}{l}\text { We have no doubts whatsoever about entering into a new coupon } \\
\text { campaign with [Brand of daily deal website] with the same conditions }\end{array}$ & 2.95 & 2.07 & 24.40 & 0.93 \\
\hline \multirow[t]{6}{*}{ Procedural fairness } & [Brand of daily deal website and their personnel] & & & & \\
\hline & $\begin{array}{l}\text { Seriously consider a merchant's objections to the supplier's policies and } \\
\text { programs }\end{array}$ & 4.67 & 1.72 & I & 0.89 \\
\hline & Provide valid reasons for any changes in policies affecting the merchant & 4.16 & 1.95 & 13.97 & 0.79 \\
\hline & Treat the merchant with respect & 5.34 & 1.54 & 15.16 & 0.83 \\
\hline & $\begin{array}{l}\text { Negotiate with the merchant every change to existing conditions (e.g. } \\
\text { number of coupons sold, etc.) }\end{array}$ & 4.82 & 1.85 & 14.01 & 0.79 \\
\hline & $\begin{array}{l}\text { Provide to the merchants the support they need to manage their coupon } \\
\text { campaign }\end{array}$ & 4.88 & 1.80 & 13.55 & 0.77 \\
\hline \multirow[t]{3}{*}{ Distributive fairness } & $\begin{array}{l}\text { The split of the benefits between the firms has been fair, given the } \\
\text { contributions each party makes }\end{array}$ & 3.21 & 2.03 & I & 0.90 \\
\hline & $\begin{array}{l}\text { My firm's share of the gain from this relationship has been fair in relation } \\
\text { to our efforts }\end{array}$ & 2.67 & 1.77 & 17.87 & 0.88 \\
\hline & $\begin{array}{l}\text { The commission retained by [Brand of daily deal website] from the } \\
\text { coupon's face value is fair }\end{array}$ & 2.96 & 1.89 & 18.61 & 0.90 \\
\hline
\end{tabular}

analyzed by using covariance-based structural equation modeling (CB-SEM) (Hair et al., 2011). CB-SEM was selected instead of partial least squares structural equation modeling (PLS-SEM) because the focus was more on confirmation than on exploration. In other terms, the priority was reproducing the covariance matrix rather than maximizing explained variance (Hair et al., 2017; Hair et al., 2019). The software IBM SPSS Amos 25 was used for this purpose. We first checked that the assumptions of normality, linearity, and homoscedasticity for running this analysis were met (Kline, 2011). Thereafter, we proceeded with the two steps comprising CB-SEM, that is, measurement model estimation and structural model estimation (Bagozzi and Yi, 2012; Byrne, 2001; Kline, 2011).

\subsection{Measurement model}

We evaluated the measurement model through a confirmatory factor analysis (Table 2). The overall goodness of fit is satisfactory (Bagozzi and Yi, 2012). In detail, $\chi^{2}$ (df $=125, p<$ 0.01 ) is equal to 192.09 , with a $\chi^{2} /$ df ratio of 1.53 , which is below the threshold of 3 (Kline, 2011). Moreover, confirmatory fit index (CFI) is 0.98 , above the suggested cutoff of 0.93 (Bagozzi and Yi, 2012). Finally, root mean square error of approximation (RMSEA) is 0.05 ( $p$ close $=0.39$ ) and standardized root mean residual (SRMR) is 0.04 , below the recommended threshold of 0.07 for both (Bagozzi and $\mathrm{Yi}$, 2012).

In addition, all standardized factor loadings are higher than the cutoff value of 0.70 , the average variances extracted (AVEs) for each latent construct are higher than 0.50, and the composite reliabilities for each latent construct are above 0.70 . Therefore, reliability and convergent validity are achieved (Fornell and Larcker, 1981). Moreover, the AVEs for each latent construct are greater than the construct's highest squared correlation with any other construct, indicating satisfactory discriminant validity (Fornell and Larcker, 1981) (Table 3).

\section{Results}

Table 4 shows the results of the structural model estimation. The model fits the data satisfactorily. Chi-square $(\mathrm{df}=623)$ is equal to 1065.56 with a $\chi^{2} / \mathrm{df}$ ratio of 1.71 , markedly below the cutoff of 3 (Kline, 2011). In addition, CFI is 0.94, above the threshold of 0.93 (Bagozzi and Yi, 2012). The RMSEA is 0.06 
[0.054-0.066] and SRMR is 0.05, showing good model fit (Bagozzi and Yi, 2012).

The results support the hypothesized chain that links campaign effectiveness to satisfaction $(\beta=0.818, p<0.01 ; H 1$ is supported) and satisfaction to the intention to renew the contract ( $\beta=0.576, p<0.01 ; H 2$ is supported). In addition, the findings demonstrate that procedural fairness has both a positive direct effect on satisfaction and a negative moderating effect on the relationship between campaign effectiveness and satisfaction $(\beta=0.235, p<0.01$ and $\beta=-0.129, p<0.01$, respectively; $H 3 a$ and $H 3 b$ are supported). Finally, the results support a direct, positive effect of distributive fairness on the intention to renew the contract $(\beta=0.312, p<0.01 ; \mathrm{H} 4 a$ is supported), but not a moderating effect of distributive fairness on the relationship between satisfaction and the intention to renew the contract $(\beta=0.033, p>0.10 ; H 4 b$ is rejected). Finally, neither of the two control variables (the number of employees and the average number of coupons sold per campaign) has significant effects.

To gain an in-depth understanding of the two hypothesized moderating effects, we applied both a simple slope analysis and the Johnson-Neyman technique. The simple slope analysis was conducted by evaluating the regression coefficients at one standard deviation above and at one standard deviation below the mean of the moderating variable (Cohen et al., 2013). The Johnson-Neyman technique was used to identify the range of values of the moderating variable for which the predictor had a statistically significant effect and the range for which it did not (Hayes and Matthes, 2009).

Regarding the moderating effect of procedural fairness (Figure 3), the slope analysis shows that when procedural fairness is high, the slope is lower, meaning that the effect of campaign effectiveness on satisfaction is lower. Moreover, the Johnson-Neyman technique highlights that there are no statistically significant transition points. Hence, the effect of campaign effectiveness on satisfaction is always significant, regardless of the level of procedural fairness.

For the moderating effect of distributive fairness (Figure 4), there is no statistical difference in the slopes, meaning that the impact of satisfaction on the intention to renew the contract is the same, regardless of the levels of distributive fairness. In addition, this effect is significant along all values of distributive fairness, as demonstrated by the Johnson-Neyman analysis.

\section{Discussion of the results}

This study shows that buyers' evaluation of discrete, timedelimited B2B transactions encompasses an assessment of both economic and social outcomes, as well as fairness. Hence, the intention to renew contracts after discrete transactions is driven by evaluations that are not based exclusively on economic outcomes as indicated by a remarkable number of past studies (Kronlid and Baraldi, 2020; Williamson, 1979). While it is well established that social bonds have a fundamental role in longterm B2B relationships, the role of social bonds has been substantially overlooked in exchanges of shorter duration (Voss et al., 2019). However, our findings show that, despite the limited timeframe of discrete B2B transactions, social outcomes along with fairness evaluations matter also in this context.

The results contribute to advancing our knowledge of the role of fairness in B2B relationships. While past studies have considered fairness only in the context of long-term relationships, highlighting its enhancement over time

Table 3 Mean, standard deviations, average variance extracted, composite reliability and squared correlations among constructs

\begin{tabular}{lcccccccc}
\hline Constructs & Mean & SD & AVE & C.R. & $\mathbf{1}$ & $\mathbf{2}$ & $\mathbf{3}$ & $\mathbf{4}$ \\
\hline 1. Campaign effectiveness & 2.54 & 1.10 & 0.65 & 0.85 & 1 & & & \\
2. Satisfaction & 3.97 & 1.81 & 0.82 & 0.95 & 0.76 & 1 & \\
3. Intention to renew the contract & 3.19 & 2.02 & 0.88 & 0.96 & 0.38 & 0.57 & 1 & \\
4. Procedural fairness & 4.77 & 1.51 & 0.66 & 0.91 & 0.12 & 0.30 & 0.22 & 1 \\
5. Distributive fairness & 2.95 & 1.76 & 0.80 & 0.92 & 0.16 & 0.38 & 0.43 & 0.39 \\
\hline
\end{tabular}

Table 4 Structural model results

\begin{tabular}{|c|c|c|c|}
\hline & Unst. coeff. & S.E. & Std. coeff. \\
\hline \multicolumn{4}{|l|}{ Hypotheses } \\
\hline H1. Campaign effectiveness $\rightarrow$ Satisfaction & $1.313^{* *}$ & 0.105 & 0.818 \\
\hline H2. Satisfaction $\rightarrow$ Intention to renew the contract & $0.647^{* *}$ & 0.074 & 0.576 \\
\hline H3a. Procedural fairness $\rightarrow$ Satisfaction & $0.269^{* *}$ & 0.059 & 0.235 \\
\hline$H 3 b$. Procedural fairness ${ }^{*}$ Campaign effectiveness $\rightarrow$ Satisfaction & $-0.177^{* *}$ & 0.068 & -0.129 \\
\hline H4a. Distributive fairness $\rightarrow$ Intention to renew the contract & $0.337^{* *}$ & 0.070 & 0.312 \\
\hline$H 4 b$. Distributive fairness ${ }^{*}$ Satisfaction $\rightarrow$ Intention to renew the contract & 0.022 & 0.035 & 0.033 \\
\hline \multicolumn{4}{|l|}{ Model fit } \\
\hline$\chi^{2}$ & \multicolumn{3}{|c|}{ 1065.56, $d f=623, p<0.01$} \\
\hline RMSEA & \multicolumn{3}{|c|}{$0.06[0.054-0.066]$} \\
\hline SRMR & \multicolumn{3}{|l|}{0.05} \\
\hline CFI & \multicolumn{3}{|l|}{0.94} \\
\hline Note: ${ }^{* *} p<0.01$ & & & \\
\hline
\end{tabular}


Figure 3 The moderating effect of procedural fairness

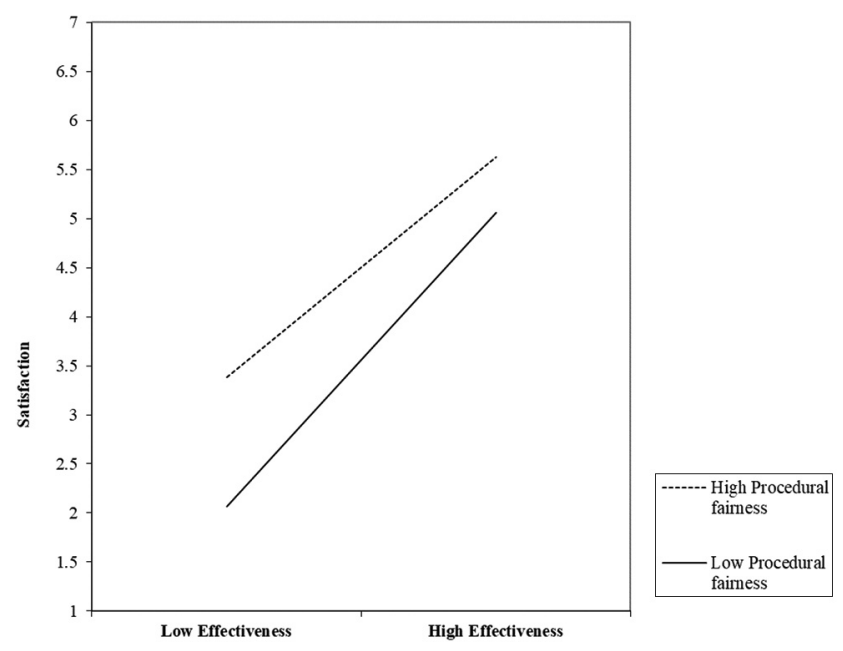

Figure 4 The moderating effect of distributive fairness

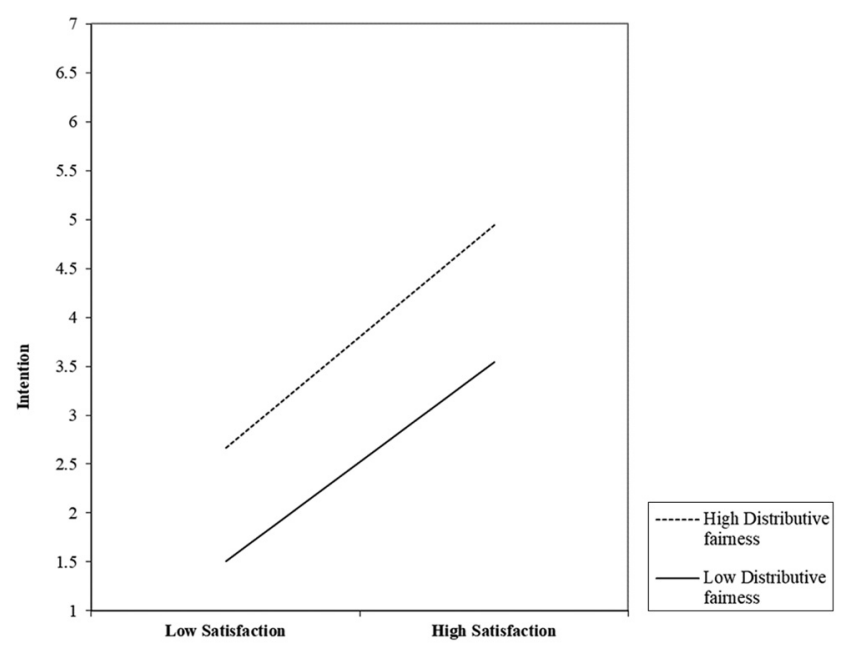

(Crosno and Dahlstrom, 2011; Jokela and Söderman, 2017), our study indicates that fairness evaluations play a role in discrete B2B transactions delimited in time. Buyers' intention to renew a contract after an initial transaction without any further commitments to transact is an important signal of the likelihood of progressing from a discrete transaction to a longterm relationship with a high level of loyalty. The results show that buyers are concerned about not only the economic and social outcomes they receive from the transaction but also fairness in terms of both fair processes and procedures and the fair sharing of outcomes.

In addition, the implication of the negative moderating effect of procedural fairness on the relationship between campaign effectiveness and satisfaction is particularly interesting because it extends our knowledge of the interplay between economic and social dimensions in discrete exchanges (Lambe et al., 2000; LaPlaca and da Silva, 2016; Maurya and Srivastava, 2020). This finding suggests that by applying fair procedures and processes, suppliers may be able to satisfy and, in turn, retain buyers, even when the buyer perceives low performance.
Hence, in contexts characterized by discrete, time-delimited transactions and uncertainty regarding outcomes (such as the context in this study), procedural fairness may serve as a partial substitute for economic outcomes. That is, when economic outcomes (campaign effectiveness) are influenced largely by external, uncontrollable conditions, the buyer seems to appreciate the supplier's efforts to behave fairly and provide as much support as possible.

We did not find any support for the negative moderating effect of distributive fairness on the relationship between satisfaction and the intention to renew the contract. Distributive fairness does not serve as a partial substitute for satisfaction because the effect of satisfaction on the intention to renew the contract is stable regardless of the level of distributive fairness. This finding disconfirms one of the propositions of fairness theory proposing that when knowledge among the parties is limited, distributive fairness acts as a heuristic reducing the influence of other factors such as relationship quality (Lind et al., 2001). Our results indicate that both satisfaction and distributive fairness have direct and significant effects on the intention to renew the contract, but there is no interaction between them. This finding suggests that even when knowledge among the parties is limited, social outcomes (satisfaction) have a significant effect on behavioral intentions, which is independent of the sharing of benefits (distributive fairness). This supports the need to consider the impact of social outcomes to understand the mechanisms underlying discrete exchanges delimited in time (Kronlid and Baraldi, 2020).

\section{Implications, limitations and suggestions for future research}

\subsection{Theoretical implications}

This study indicates that SET can be applied to short-term exchanges. A core tenet of SET is that evaluations of economic and social outcomes over time determine the development of long-term relationships (Blau, 1964; Emerson, 1976; Lambe et al., 2001). However, past research claims that SET cannot explain short-term exchanges (Lambe et al., 2001). This study applies SET to discrete, time-delimited transactions by complementing evaluations of outcomes with evaluations of fairness. The intention to renew a contract based on discrete, time-delimited transactions is therefore the result of both fair processes and procedures and fair sharing of benefits in addition to economic outcomes (campaign effectiveness) and social outcomes (satisfaction).

Further, this study emphasizes the importance of including fairness in studies of short-term B2B relationships. Past conceptual studies of fairness assert that fairness evaluations arise from the early stages of buyer-supplier relationships (Crosno and Dahlstrom, 2011; Lind et al., 2001). However, this claim has not been tested empirically. Our study highlighting both the direct and the moderating effects of fairness underlines both the importance and the relevance of fairness considerations in short-term B2B relationships.

In broader terms, we contribute to advancing our knowledge of B2B relationship governance, not only in the case of short-term exchanges. As pointed out in a recent literature review (Bouazzaoui et al., 2020), even if fairness is an old concept in the context of 
inter-organizational relationships, it has been largely ignored for a long time, despite having regained remarkable appeal in the past decade. For example, Poppo and Zhou (2014) argue that governance of relationships (e.g. formal versus informal) must be matched with managerial practices in such a way that fairness is supported. The authors find that "fairness considerations are an important determinant of exchange performance and partially account for the efficacy of contracting" (Poppo and Zhou, 2014, p. 1522). A contract - regardless of whether it is formal or informal will not work properly unless it is perceived as fair. Even though recent studies emphasize the importance of fairness in business relationships, the concept of fairness has not been included in theories and theoretical frameworks. One exception is Husted and Folger (2004), who link fairness to transaction cost economics and argue that whether a governance mechanism is evaluated as fair or unfair affects the efficiency of the governance mechanism in terms of minimizing transaction costs. Thus, according to these authors' arguments, the predictive power of a theory aimed at explaining business transactions and business relationships depends on the actors' perceived level of fairness. However, it remains a theoretical challenge to properly include fairness in theories of business relationships. Our study highlighting how SET and fairness can be integrated to explain short-term B2B exchanges is one step in this direction.

\subsection{Managerial implications}

When engaging in discrete, time-delimited B2B transactions, suppliers may be tempted to focus on the economic dimensions of the exchange, while moving the social and relational components to the background. For example, this tendency is emphasized in the case of digital transactions, where a reversion to transactional orientation from a relational orientation often emerges. However, the results of this study indicate that social outcomes and the perceptions of fairness play a substantial role in explaining how actors evaluate discrete, time-delimited transactions. Both economic and social evaluations have direct and specific effects on buyers' evaluation and intention to renew the contract for future transactions.

Managers responsible for $\mathrm{B} 2 \mathrm{~B}$ transactions and relationships should be concerned about how all actors perceive fairness, and focus on how discrete transactions and relationships in the early stages can integrate considerations of fairness in relationship management. Finding the right balance between the economic and social mechanisms and recognizing the distinct roles of procedural and distributive fairness are important managerial issues. A sense of procedural unfairness may undermine good economic performance, and a high level of procedural fairness may substitute for weak economic performance. Procedural fairness may thus be used as a buffer in case the economic performance is below buyers' expectations. In a situation with high procedural fairness, the buyer will be less inclined to blame the supplier for weak economic performance. Therefore, managers should pay attention to how contracts influence procedural fairness. Samaha et al. (2011, p. 99) describe unfairness as "relationship poison" and argue that the effectiveness of contracts depends on the level of fairness. In negotiating contracts, managers should be concerned with developing contracts that are considered fair by both parties, which may in turn contribute to a high level of procedural fairness.
Distributive fairness affects the intention to renew the contract, but it does not act as a buffer for low social outcomes. In other terms, even if the supplier negotiates favorable economic conditions for the buyer (e.g. lower prices), this will not interfere with the buyer's evaluations of the social outcomes, which are directly linked to the intention to renew the contract. Therefore, managers are urged to focus simultaneously on both economic and social outcomes. Sharing economic outcomes fairly is not sufficient to secure the buyer's intention to renew the contract.

\subsection{Limitations and suggestions for future research}

The study has its limitations. The context of social couponing has allowed us to study discrete, time-delimited transactions. Firms will often buy social couponing campaigns in periods with low demand or access capacity, and firms may not consider this as a regular advertising and sales activity. The fact that $72.4 \%$ of the sampled firms with complete answers had performed one or two campaigns, and only $11.3 \%$ had performed six or more campaigns illustrate that the firms do not buy campaigns on a regular basis. However, a limitation is that firms may have less emphasis on this kind of transactions compared to other discrete transactions that represent regular business activities. Firms may therefore be less concerned with both outcomes and fairness in such transactions. The growth in online B2B transactions should encourage future studies to address outcomes and fairness in discrete transactions representing regular business activities.

The choice of one setting - social couponing - has its pros and cons. We have been able to focus on one specific type of transaction that is similar for all respondents. With our focus on outcomes and fairness in discrete, time-delimited transactions, this approach has reduced the number of external, uncontrollable factors in the data. With limited prior knowledge in this area, we have emphasized the internal validity of the results, and the empirical support for most of the hypotheses gives credibility to our theoretical model. On the other hand, it limits the generalizability of the results. The respondents are small firms and they represent different industries. Larger firms may have more bargaining power than small firms in their negotiations with the daily deal websites and get more favorable campaign terms. This may influence their evaluations of both outcomes and fairness. Although the respondents buy the same service from the daily deal websites, they represent different industries and the social coupons are targeted at different customer segments. The knowledge of and familiarity with social couponing may vary between different customer groups, which may in turn, affect the number of sold coupons. We should therefore be cautious in generalizing the results to discrete, time-delimited B2B transactions in general. Future studies should therefore test a similar theoretical model across multiple types of transactions, include more variation in firm sizes, and possibly study one industry at a time to increase the external validity.

We collected survey data approximately one year after the firms' social couponing campaigns had been completed to ensure that the time span from end of campaign to questionnaire response was similar for all respondents. However, a limitation with survey data is that we were unable to study how outcomes and fairness develop throughout the contract period. Therefore, future studies should follow relationships during the contract or over an extended period to track how fairness and outcomes jointly develop and to identify 
specific factors to increase our understanding of the interplay between outcomes and fairness. Studies on the dynamic nature of fairness may offer a broader understanding of the antecedents to and consequences of fairness. In a similar way, procedural fairness may be more important than distributive fairness in some stages of the exchange and vice versa, and longitudinal studies can also reveal the interplay between procedural and distributive fairness.

This study is among the first to link fairness to economic and social outcomes in discrete, time-delimited transactions. Given that most B2B markets are characterized by recurring transactions and long-term relationships, we encourage future studies to apply a similar model in settings in which recurrent transactions and long-term relationships are more common. The importance of fairness may differ in discrete transactions compared to long-term relationships and the importance may vary during different relationship stages.

Ariño and Ring (2010) find that fairness issues during negotiations in alliance formations were related to the decision to terminate further negotiations and not establish an alliance. In other words, fairness perceptions largely affected the decision of whether to form the alliance. An interesting avenue for further research is to gain a deeper understanding of how negotiations can be linked to fairness. Negotiations in B2B transactions and relationships are an ongoing process that does not end with the decision to agree on a transaction or to form a relationship because negotiations will continue throughout all stages of the transaction and the relationship. Negotiations can be carried out in different ways and with different negotiation strategies and tactics, and future studies should investigate whether some negotiation strategies and tactics are linked to the development of fairness and unfairness.

\section{Conclusion}

The purpose of this study was to investigate how evaluations of outcomes and fairness affected the intention to renew a contract after discrete, time-delimited transactions. Despite the growth of such B2B transactions, the underlying governance mechanisms remain largely unknown. The results show that campaign effectiveness (economic outcome) has a direct effect on satisfaction (social outcome), which in turn affects the intention to renew the contract. In addition, procedural fairness has both a positive direct effect on satisfaction and a negative moderating effect on the relationship between campaign effectiveness and satisfaction, and distributive fairness has a positive effect on the intention to renew the contract. The results confirm that assessments of discrete transactions encompass both economic and social outcomes, and in addition, fairness. The proposed model substantiates the effectiveness of combining SET and fairness theory to predict the outcomes of discrete $\mathrm{B} 2 \mathrm{~B}$ transactions.

\section{References}

Ariño, A. and Ring, P.S. (2010), "The role of fairness in alliance formation", Strategic Management fournal, Vol. 31 No. 10, pp. 1054-1087.
Armstrong, J.S. and Overton, T.S. (1977), "Estimating nonresponse bias in mail surveys", fournal of Marketing Research, Vol. 14 No. 3, pp. 396-402.

Bagozzi, R.P. and Yi, Y. (2012), "Specification, evaluation, and interpretation of structural equation models", fournal of the Academy of Marketing Science, Vol. 40 No. 1, pp. 8-34.

Bennett, R., Härtel, C.E. and McColl-Kennedy, J.R. (2005), "Experience as a moderator of involvement and satisfaction on brand loyalty in a business-to-business setting", Industrial Marketing Management, Vol. 34 No. 1, pp. 97-107.

Berezina, K., Semrad, K.J., Stepchenkova, S. and Cobanoglu, C. (2016), "The managerial flash sales dash: is there advantage or disadvantage at the finish line?", International Fournal of Hospitality Management, Vol. 54, pp. 12-24.

Blau, P.M. (1964), Exchange and Power in Social Life, New York, NY.

Bouazzaoui, M., Wu, H.-J., Roehrich, J.K., Squire, B. and Roath, A.S. (2020), "Justice in inter-organizational relationships: a literature review and future research agenda", Industrial Marketing Management, Vol. 87, pp. 128-137.

Brown, J.R., Cobb, A.T. and Lusch, R.F. (2006), "The roles played by interorganizational contracts and justice in marketing channel relationships", fournal of Business Research, Vol. 59 No. 2, pp. 166-175.

Byrne, B.M. (2001), "Structural equation modeling with AMOS, EQS, and LISREL: comparative approaches to testing for the factorial validity of a measuring instrument", International fournal of Testing, Vol. 1 No. 1, pp. 55-86.

Cannon, J.P. and Perreault, W.D. Jr (1999), "Buyer-seller relationships in business markets", fournal of Marketing Research, Vol. 36 No. 4, pp. 439-460.

Cassia, F., Magno, F. and Ugolini, M. (2015), "The perceived effectiveness of social couponing campaigns for hotels in Italy", International Fournal of Contemporary Hospitality Management, Vol. 27 No. 7, pp. 1598-1617.

Cohen, J., Cohen, P., West, S.G. and Aiken, L.S. (2013), Applied Multiple Regression/Correlation Analysis for the Behavioral Sciences, Lawrence Erlbaum, Mahwah, NJ.

Cox, C. (2015), "Consumer experiences of accommodation deals purchased via social coupon promotions: an Australian perspective", Fournal of Hospitality Marketing E Management, Vol. 24 No. 6, pp. 609-632.

Cropanzano, R. and Mitchell, M.S. (2005), "Social exchange theory: an interdisciplinary review", fournal of Management, Vol. 31 No. 6, pp. 874-900.

Crosno, J.L. and Dahlstrom, R. (2011), "Fairness heuristics and the fundamental transformation in interorganizational relationships", Fournal of Business-to-Business Marketing, Vol. 18 No. 4, pp. 313-334.

Dong, X., Zou, S., Sun, G. and Zhang, Z. (2019), "Conditional effects of justice on instability in international joint ventures", Fournal of Business Research, Vol. 101, pp. 171-182.

Eggert, A. and Ulaga, W. (2002), “Customer perceived value: a substitute for satisfaction in business markets?", fournal of Business \& Industrial Marketing, Vol. 17 Nos 2/3, pp. 107-118.

Emerson, R.M. (1976), "Social exchange theory", Annual Review of Sociology, Vol. 2 No. 1, pp. 335-362. 
Fornell, C. and Larcker, D.F. (1981), "Evaluating structural equation models with unobservable variables and measurement error", fournal of Marketing Research, Vol. 18 No. 1, pp. 39-50.

Griffith, D.A., Harvey, M.G. and Lusch, R.F. (2006), "Social exchange in supply chain relationships: the resulting benefits of procedural and distributive justice", fournal of Operations Management, Vol. 24 No. 2, pp. 85-98.

Gustafson, B.M., Pomirleanu, N., Mariadoss, B.J. and Johnson, J.L. (2019), "The social buyer: a framework for the dynamic role of social media in organizational buying", Fournal of Business Research, Vol. 125, pp. 1-9.

Hair, J.F., Hult, G.T.M., Ringle, C.M. and Sarstedt, M. (2017), A Primer on Partial Least Squares Structural Equation Modeling (PLS-SEM), Sage, Thousand Oaks, CA.

Hair, J.F., Ringle, C.M. and Sarstedt, M. (2011), "PLS-SEM: indeed a silver bullet", fournal of Marketing Theory and Practice, Vol. 19 No. 2, pp. 139-151.

Hair, J.F., Risher, J.J., Sarstedt, M. and Ringle, C.M. (2019), "When to use and how to report the results of PLS-SEM", European Business Review, Vol. 31 No. 1, pp. 2-24.

Håkansson, H. (1982), International Marketing and Purchasing of Industrial Goods: An Interaction Approach, Wiley, Chichester.

Hayes, A.F. and Matthes, J. (2009), "Computational procedures for probing interactions in OLS and logistic regression: SPSS and SAS implementations", Behavior Research Methods, Vol. 41 No. 3, pp. 924-936.

Hofacker, C., Golgeci, I., Pillai, K.G. and Gligor, D.M. (2020), "Digital marketing and business-to-business relationships: a close look at the interface and a roadmap for the future", European Fournal of Marketing, Vol. 54 No. 6, pp. 1-19.

Homans, G.C. (1958), "Social behavior as exchange", American fournal of Sociology, Vol. 63 No. 6, pp. 597-606.

Human, G. and Naudé, P. (2014), "Heterogeneity in the quality-satisfaction-loyalty framework", Industrial Marketing Management, Vol. 43 No. 6, pp. 920-928.

Husted, B.W. and Folger, R. (2004), "Fairness and transaction costs: the contribution of organizational justice theory to an integrative model of economic organization", Organization Science, Vol. 15 No. 6, pp. 719-729.

Janita, M.S. and Miranda, F.J. (2013), "The antecedents of client loyalty in business-to-business (B2B) electronic marketplaces", Industrial Marketing Management, Vol. 42 No. 5, pp. 814-823.

Jap, S.D. (2001), "Perspectives on joint competitive advantages in buyer-supplier relationships", International Fournal of Research in Marketing, Vol. 18 Nos 1/2, pp. 19-35.

Jokela, P. and Söderman, A. (2017), "Re-examining the link between fairness and commitment in buyer-supplier relationships", fournal of Purchasing and Supply Management, Vol. 23 No. 4, pp. 268-279.

Kim, K.T., Lee, J.S. and Lee, S.-Y. (2019), "Chain reactions of a collaborative buyer-supplier relationship: the mediating role of relationship quality on innovation performance", Total Quality Management \& Business Excellence, Vol. 30 Nos 11/12, pp. 1319-1337.

Kim, K.-T., Lee, J.S. and Lee, S.-Y. (2017), "The effects of supply chain fairness and the buyer's power sources on the innovation performance of the supplier: a mediating role of social Capital accumulation", fournal of Business E Industrial Marketing, Vol. 32 No. 7, pp. 987-997.
Kline, R.B. (2011), Principles and Practice of Structural Equation Modeling, 3rd ed., Guilford, New York, NY.

Kronlid, C. and Baraldi, E. (2020), "Time-constrained interactions in public-private collaboration projects. The case of ENABLE”, Fournal of Business $\mathcal{E}$ Industrial Marketing, Vol. 35 No. 6, pp. 1037-1050.

Kumar, V. and Rajan, B. (2012), "Social coupons as a marketing strategy: a multifaceted perspective", fournal of the Academy of Marketing Science, Vol. 40 No. 1, pp. 120-136.

Kumar, N., Scheer, L.K. and Steenkamp, J.-B.E. (1995), "The effects of supplier fairness on vulnerable resellers", fournal of Marketing Research, Vol. 32 No. 1, pp. 54-65.

Lambe, C.J., Spekman, R.E. and Hunt, S.D. (2000), "Interimistic relational exchange: conceptualization and propositional development", Fournal of the Academy of Marketing Science, Vol. 28 No. 2, pp. 212-225.

Lambe, C.J., Wittmann, C.M. and Spekman, R.E. (2001), "Social exchange theory and research on business-tobusiness relational exchange", fournal of Business-to-Business Marketing, Vol. 8 No. 3, pp. 1-36.

LaPlaca, P. and da Silva, R.V. (2016), "B2B: a paradigm shift from economic exchange to behavioral theory: a quest for better explanations and predictions”, Psychology $\mathcal{G}$ Marketing, Vol. 33 No. 4, pp. 232-249.

Levin, E., Quach, T.N. and Thaichon, P. (2019), "Enhancing client-agency relationship quality in the advertising industryan application of project management", fournal of Business $\mathcal{E}$ Industrial Marketing, Vol. 34 No. 2, pp. 463-473.

Lind, E.A., Kray, L. and Thompson, L. (2001), "Primacy effects in justice judgments: testing predictions from fairness heuristic theory", Organizational Behavior and Human Decision Processes, Vol. 85 No. 2, pp. 189-210.

Ling-Yee, L. (2010), "Encouraging extra-role behavior in a channel context: the role of economic-, social-, and justicebased sharedness mechanisms", Industrial Marketing Management, Vol. 39 No. 2, pp. 195-201.

Macneil, I.R. (1980), The New Social Contract: An Inquiry into Modern Contractial Relations, Yale University Press, New Haven CT.

Maurya, D. and Srivastava, A.K. (2020), "Relationship between governance mechanisms and contract performance", International fournal of Productivity and Performance Management, Vol. 69 No. 1, pp. 44-60.

Morgan, R.M. and Hunt, S.D. (1994), "The commitmenttrust theory of relationship marketing", fournal of Marketing, Vol. 58 No. 3, pp. 20-38.

Mutonyi, S., Beukel, K. and Hjortsø, C.N. (2018), "Relational factors and performance of agrifood chains in Kenya", Industrial Marketing Management, Vol. 74, pp. 175-186.

Narasimhan, R., Nair, A., Griffith, D.A., Arlbjørn, J.S. and Bendoly, E. (2009), "Lock-in situations in supply chains: a social exchange theoretic study of sourcing arrangements in buyer-supplier relationships", Fournal of Operations Management, Vol. 27 No. 5, pp. 374-389.

Nevin, J.R. (1995), "Relationship marketing and distribution channels: exploring fundamental issues", fournal of the Academy of Marketing Science, Vol. 23 No. 4, pp. 327-334.

Oliver, R.L. (1996), Satisfaction: A Behavioral Perspective on the Consumer, McGraw Hill, New York, NY. 
Padilla, R.S., Milton, S.K., Johnson, L.W. and Nyadzayo, M. W. (2017), "Impact of service value on satisfaction and repurchase intentions in business-to-business cloud computing", Service Science, Vol. 9 No. 1, pp. 5-13.

Peppard, J. and Rylander, A. (2006), "From value chain to value network: insights for mobile operators", European Management fournal, Vol. 24 Nos 2/3, pp. 128-141.

Peters, L.D. and Pressey, A.D. (2016), "The co-ordinative practices of temporary organisations", fournal of Business $\mathcal{E}$ Industrial Marketing, Vol. 35 No. 6, pp. 1037-1050.

Poppo, L. and Zhou, K.Z. (2014), "Managing contracts for fairness in buyer-supplier exchanges", Strategic Management fournal, Vol. 35 No. 10, pp. 1508-1527.

Roberts, J. and Merrilees, B. (2007), "Multiple roles of brands in business-to-business services", fournal of Business $\mathcal{E}$ Industrial Marketing, Vol. 22 No. 6, pp. 410-417.

Ruiz-Martínez, A., Frasquet, M. and Gil-Saura, I. (2019), "How to measure B2B relationship value to increase satisfaction and loyalty", Fournal of Business E Industrial Marketing, Vol. 34 No. 8, pp. 1866-1878.

Samaha, S.A., Palmatier, R.W. and Dant, R.P. (2011), "Poisoning relationships: perceived unfairness in channels of distribution", fournal of Marketing, Vol. 75 No. 3, pp. 99-117.

Selviaridis, K. (2016), “Who's to blame or praise? Performance attribution challenges in outsourced service provision in supply chains", Supply Chain Management: An International fournal, Vol. 21 No. 5, pp. 513-533.

Shanka, M.S. and Buvik, A. (2019), "When does relational exchange matters? Social bond, trust and satisfaction",
Fournal of Business-to-Business Marketing, Vol. 26 No. 1, pp. 57-74.

Sheppard, B., Lewicki, R. and Minton, J. (1992), Organizational fustice, Lexington Books, New York, NY.

Sigala, M. (2013), "A framework for designing and implementing effective online coupons in tourism and hospitality", Fournal of Vacation Marketing, Vol. 19 No. 2, pp. 165-180.

Voss, K.E., Tanner, E.C., Mohan, M., Lee, Y.-K. and Kim, H. K. (2019), "Integrating reciprocity into a social exchange model of inter-firm B2B relationships", fournal of Business $\mathcal{E}$ Industrial Marketing, Vol. 34 No. 8, pp. 1668-1680.

Wagner, S.M., Coley, L.S. and Lindemann, E. (2011), 'Effects of suppliers' reputation on the future of buyersupplier relationships: the mediating roles of outcome fairness and trust", fournal of Supply Chain Management, Vol. 47 No. 2, pp. 29-48.

Williams, P., Khan, M.S., Ashill, N.J. and Naumann, E. (2011), "Customer attitudes of stayers and defectors in B2B services: are they really different?", Industrial Marketing Management, Vol. 40 No. 5, pp. 805-815.

Williamson, O.E. (1979), "Transaction-cost economics: the governance of contractual relations", The fournal of Law and Economics, Vol. 22 No. 2, pp. 233-261.

Wölfel, J. and Grosse-Ruyken, P.T. (2019), "Fairness of the NPD partnership's financial distribution pie", fournal of Business $\mathcal{E}$ Industrial Marketing, Vol. 34 No. 5.

\section{Corresponding author}

Fabio Cassia can be contacted at: fabio.cassia@univr.it 